\title{
Population Dynamics and Genetics of Gerbillus nigeriae in Central Sahel: Implications for Rodent Pest Control
}

\author{
Hima Karmadine ${ }^{1, ~ *}$, Granjon Laurent ${ }^{2}$, Gauthier Philippe ${ }^{2}$, Ndiaye Arame $^{3}$, Brouat Carine ${ }^{2}$, \\ Dobigny Gauthier ${ }^{2}$ \\ ${ }^{1}$ Departement of Biology, Abdou Moumouni University (UAM), Niamey, Niger \\ ${ }^{2}$ Center of Biology for Population Management (CBGP), Campus International de Baillarguet, Montferrier-sur-Lez, France \\ ${ }^{3}$ Laboratoy for Sudano-Sahelian Animal Populations, BIOPASS (UCAD-IRD-CIRAD-ISRA), Dakar, Sénégal
}

\section{Email address:}

karmadine@gmail.com (H. Karmadine)

${ }^{*}$ Corresponding author

\section{To cite this article:}

Hima Karmadine, Granjon Laurent, Gauthier Philippe, Ndiaye Arame, Brouat Carine, Dobigny Gauthier. Population Dynamics and Genetics of Gerbillus nigeriae in Central Sahel: Implications for Rodent Pest Control. Ecology and Evolutionary Biology.

Vol. 4, No. 4, 2019, pp. 45-54. doi: 10.11648/j.eeb.20190404.11

Received: September 17, 2019; Accepted: October 21, 2019; Published: October 31, 2019

\begin{abstract}
Gerbillus nigeriae is a sand-dwelling and semi-arid adapted rodent species restricted to the West African Sahel where it causes extensive damages to cereal crops such as millet and sorghum. It also displays one of the most extensive floating chromosomal polymorphisms currently known in mammals, showing a non-random spatial distribution of diploid numbers $(2 \mathrm{~N})$. We combined population dynamics and genetics to determine dispersal and mobility parameters of G. nigeriae in the species distribution range characterized by low $2 \mathrm{~N}$. To do so, we performed a three-year long population survey at Gangara, in the central east Niger. We used both time-dependent monitoring trough capture-mark-recapture (CMR) methods and genetic analyses performed on the 134 monitored individuals. CMR results showed low to very low population densities (maximum 27.5 individuals/ha) throughout the study. Abundance cycle was single-phased and strongly dependent on rainfall patterns. Mobility parameters showed very low individual mobility, with means of distance between successive (re) captures (DRS) and maximal distance between (re) captures (DMR) of 7.8 and 14.4 meters, respectively. Genetic analyses revealed significant isolation by distance as well as spatial structuration, thus confirming poor dispersal capacity. Our results are discussed in terms of rodent pest control in arid areas of Niger where cereal crops production is crucial for human food security.
\end{abstract}

Keywords: Pest Rodent, Gerbillus nigeriae, Abundance, Mobility, Dispersal, Rodent Control, Niger

\section{Introduction}

Gerbillus nigeriae (Muridae, Gerbillinae) is a sanddwelling rodent species that lives within a narrow Sahelian strip from Chad to the Mauritanian coast [1,2]. This semiarid adapted species is one of the most abundant and common rodent pests of cereal crops in the West African Sahel. Its diet consists mainly in seeds and, it causes major damage to seedlings and young plants in the field, as well as household and village food stocks of millet, sorghum, cowpea and peanut [3-5]. As an illustration, the destruction of up to $60 \%$ of millet seedlings was recorded in the Tanout department in the central-east part of Niger, and local but complete destruction is routinely reported in villages throughout Niger [6].

Methods used by local farmers to manage this rodent pest are often ineffective. In particular, they usually act too late, namely when rodents have already reached too high density to be efficiently controlled. Therefore, it appears essential to design preventive control strategies for G. nigeriae. In order to do so we require a better understanding of local demographic and spatial parameters (mobility, abundance, dispersal, structure) [7]. However, despite its importance for food security, there is a paucity of research on $G$. nigeriae in Sahelian countries $[3,4,8]$.

A population dynamics survey was carried out in Kollo in 
the South Western part of Niger, which, allowed the authors to determine various demographic parameters of this population as well as some of the factors which may be responsible for population abundance variations. So far, no data are available for $G$. nigeriae population dynamics in eastern and central part of Niger which is mostly inhabited by rural populations that are almost fully dependent on tropical rain-fed cereal crops that are susceptible to severe damage by $G$. nigeriae. It is unknown whether the results obtained in Kollo can be generalized to all the country for two main reasons. First, rainfall features as well as climate change impacts in south-west Niger are not the same that those observed in central and eastern parts of the country [9]. Second, $G$. nigeriae displays one of the most extensive chromosomal polymorphism (i.e. due to centric fusions [10]) known in mammals since its diploid number $(2 \mathrm{~N})$ ranges from $2 \mathrm{~N}=60-74[11,12]$. These karyotypic variations show a non-random spatial distribution with major biogeographic groups being defined according to their respective $2 \mathrm{~N}$ values ranges (i.e., "high $2 \mathrm{~N}$ values", $2 \mathrm{~N}=70-74$; "intermediate $2 \mathrm{~N}$ values", $2 \mathrm{~N}=65-69$; "low $2 \mathrm{~N}$ values", $2 \mathrm{~N}=60-64$ [2]). In Niger, two groups of very different chromosomal variants of G. nigeriae are found (Hima et al., 2011): high 2N cytotypes (i.e. $2 \mathrm{~N}=70-74$ ) characterize the western part of the country, while low $2 \mathrm{~N}$ cytotypes (i.e. $2 \mathrm{~N}=60-64$ ) inhabit the central and eastern regions of Niger. Such genomic differences may be associated with divergent eco-evolutionary paths and potential differences in physiology, behaviour and social structure [13], hence population dynamics.

In this context, we conducted a three year-long monitoring survey of Gerbillus nigeriae in central east Niger through a combination of Capture-Mark-Recapture (CMR) and microsatellite DNA-based genetics analyses. The aim of our study was to identify relevant periods and spatial scales for a better management of this major Sahelian rodent pest species.

\section{Material and Methods}

\subsection{Monitoring Framework and Sampling}

A Capture-Mark-Recapture experiment was undertaken in a sandy soil millet field close to the village of Gangara $\left(14^{\circ} 36^{\prime} \mathrm{N}, 08^{\circ} 30^{\prime} \mathrm{E}\right)$ in the central-east part of Niger from February 2008 to June 2011 . It consisted of a $150 \times 150 \mathrm{~m}$ parcel (i.e. 2.25 ha) where 256 locally made wire mesh traps were arranged in 16, 10 meter-spaced, lines. Two consecutive traps were separated by ten meters, thus making a grid of 225 squares of $100 \mathrm{~m}^{2}$ each. Monitoring was conducted during three and a half years with three sampling periods per year: in the middle of the dry season (February), at the beginning and the end of the rainy season (June and October, respectively). Each trapping session consisted in five consecutive nights with peanut butter-baited traps set in the afternoon and checked early in the morning. Rodents were caught alive, weighted, measured, and recorded for their reproductive status (i.e. male vs. female, juvenile $v s$. adults, internal $v s$. external testicle, pregnant and suckling females). They were marked by phalange amputation and ear notch [14] then released at their exact capture point after which we systematically waited for the released individuals to enter safely into a burrow. Phalanges and ears pieces from individual marking procedures were collected and preserved in ethanol for further genetics analyses.

\subsection{Population Dynamics}

Population sizes at each sampling period were estimated using the "Minimum Number Alive" method (MNA) [15]. MNA is defined as the number of individuals caught in a capture session, plus those that were not caught at that time but were caught both previously and subsequently within the device. It is a widely used index to assess population size with capture-mark-recapture data [16]. Population density was obtained by dividing each MNA value by the area of the grid increased with an "attraction area" which corresponds to a surface that surpasses the grid on each side by the equivalent of half the distance between successive recapture (DRS; see below) [17]. We then tested correlations between population density fluctuations and monthly rainfalls that were locally recorded using a rain gauge located in the village.

Individual mobility parameters were estimated by calculating (i) the mean distance between successive (re) captures (DRS), and (ii) the mean maximal distance between (re) captures (DMR), of all recaptured individuals during one given sampling temporal session. These distances (DRS and DMR) were calculated for all individuals as well as for sex and age categories (male vs. female; young vs. adult individual). Finally, instantaneous (i.e. within one trapping sessions) and cumulative (i.e. over the entire trapping history of any individual) mean home range sizes were estimated according to the "Minimum Convex Polygon" [18, 19].

\subsection{Population Genetics}

Genomic DNA was extracted from phalanx or ear tissue samples collected during individual marking procedures using the Qiagen DNeasy Blood and Tissue Kit. It was then used as a template for individual multiplex genotyping at 12 $G$. nigeriae species-specific microsatellite loci, (GN01, GN11, GN19, GN21, GN24, GN27, GN29, GN37, GN48, GN51, GN62 and GN78) that were previously developed [20]. Microsatellite repeats were then genotyped on an Applied Biosystems ABI 3130xl Genetic Analyzer (Life Technologies) and analysed using GeneMapper v.4.0.

Genotypic linkage disequilibrium and deviation from Hardy-Weinberg equilibrium (HWE) were investigated for each pair of loci and for each locus, respectively, using Genepop v.4.7 [21]. We corrected for multiple testing by the false discovery rate approach [22] implemented in the QVALUE R-package [23]. Genetic diversity was estimated over all loci by calculating unbiased [24] expected $\left(H_{E}\right)$ and observed $\left(H_{O}\right)$ heterozygosities as well as the allelic richness. Deviation from HWE was quantified by computing $F_{I S}$ using 
Fstat program $[25,26]$.

We tested individuals' relatedness within annual samples using SPAGEDI v.1.4 [27]. To do so, we computed the kinship coefficient of Loiselle $(p)$ [28] between all pairs of individuals within annual samples, using the whole sample (i.e. all individuals sampled throughout the three year-long monitoring period) as the dataset of reference for allelic frequencies. The corresponding histograms were plotted in $\mathrm{R}$ v.3.5.1 [29].

Genetic differentiation was evaluated by comparing $F_{S T}$ values between pairs of sub-samples in Genepop v.4.7 [25, 21]. To assess isolation by distance (IBD) pattern, we tested for the correlation between pairwise geographical (logtransformed) distances and genetic differentiation between individuals, using a Mantel test (10,000 permutations). Genetic differentiation between individuals was estimated using $\hat{e}$ statistics [30], which present a lower but slightly biased variance in contrast to $\hat{a}$ statistics [31]. Confidence intervals of IBD regression slopes were obtained using the ABC bootstrap method [32, 30] while plots were obtained under R v.3.5.1. [29]. IBD was investigated over the whole sample. The mean effective dispersal distance was estimated using the slope of IBD regression, which is inversely proportional to the product of effective density $\left(\mathrm{D}_{e}\right.$, estimated as the average density of the population) and the mean squared parent-offspring dispersal distance $\left(\sigma^{2}\right)($ IBD slope $=$ $\left.1 / 4 \pi \mathrm{D} \sigma^{2} ;[21]\right)$. We tested for sex biased dispersal using Fstat program [26], and by comparing spatial autocorrelation patterns for males and females, using SPAGEDI and the Kinship coefficient of Loiselle [27, 28].

\section{Results}

\subsection{Annual Variations of Population Density and Cycle of Abundance}

Trapping effort was constant at a rate of 256 trap-nights per day, thus making 1,280 trap-nights per temporal session and a total effort of 14,080 trap-nights for the 11 sessions conducted from 2008 to 2011 . In total, 146 individuals were captured (Table 1), thus representing an overall trapping success of $1.13 \%$. Though globally low, important annual (between sampling periods from the same year) and interannual (between sampling periods of different years) variations in trapping success were noted: density peaks were observed in June during years 2008 and 2011, and in February during years 2009 and 2010. The minimum of population density was always observed in October.

Table 1. Overall trapping success, capture results and rodent abundance for each sampling session.

\begin{tabular}{llllll}
\hline & Captures & Recaptures & Trapping success (\%) & Number of individuals & Estimated numbers of individuals (MNA) \\
\hline February 2008 & 5 & 1 & 0,4 & 4 & 4 \\
June 2008 & 34 & 10 & 2,65 & 24 & 24 \\
October 2008 & 2 & 0 & 0,15 & 2 & 4 \\
February 2009 & 61 & 7 & 4,76 & 54 & 68 \\
June 2009 & 40 & 14 & 3,12 & 26 & 26 \\
October 2009 & 0 & 0 & 0 & 0 & 1 \\
February 2010 & 8 & 2 & 0,62 & 6 & 6 \\
June 2010 & 5 & 2 & 0,4 & 3 & 3 \\
October 2010 & 1 & 0 & 0,08 & 1 & 1 \\
February 2011 & 4 & 1 & 0,31 & 3 & 3 \\
June 2011 & 43 & 6 & 2,89 & 37 & 37 \\
\hline
\end{tabular}

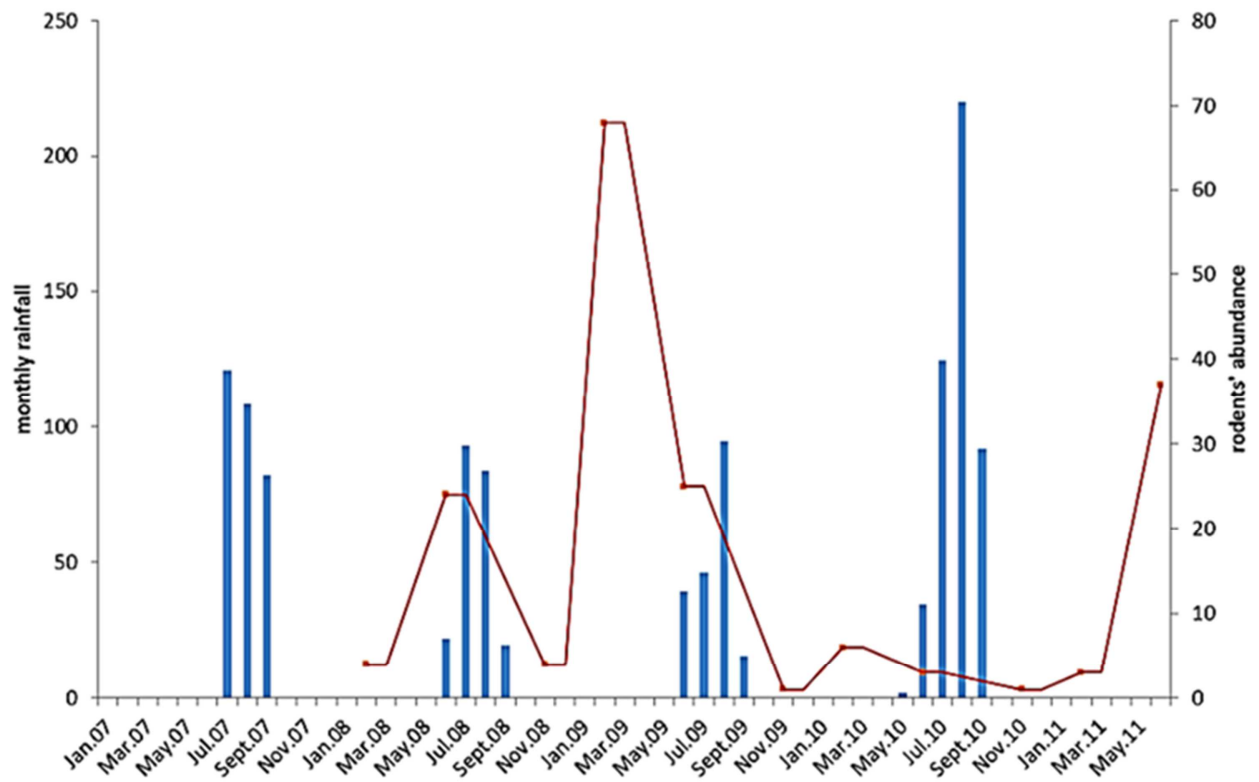

Figure 1. Cycle of abundance's variations and rain fed amount throughout the monitoring period. 
The maximal number of individuals that were present within our CMR device was observed in February 2009 (N caught $=54 ; \mathrm{MNA}=68)$, whereas the absolute minimum $(\mathrm{N}$ $=1$ ) was recorded in November 2009 (Figure 1). Along the study period, densities ranged between 0.44 (October 2009 and 2010) and 30 (February 2009) individuals/ha. Our results show a single-phase cycle, with maximum abundance reached during, or at the end of, the dry season, between February and June. From this period, the number of individuals tends to decrease until it reaches the minimum of the year towards the end of the rainy season (OctoberNovember).

The relationship between annual population densities and cumulative rainfall (Figure 1) suggests that the less it has rained during the previous year, the more precocious is the peak of abundance ( $218 \mathrm{~mm}$ cumulative rainfall in 2008 for 68 individuals observed in February 2009). In contrast, higher rainfall leads to a later peak of abundance $(311 \mathrm{~mm}$ and $473 \mathrm{~mm}$ of rainfall in 2007 and 2010, for 24 and 27 individuals in June 2008 and 2011, respectively). It also appears that after two consecutive poor rainy seasons, population density may decrease significantly (a maximum of 6 individuals recorded in 2010 following the weak rainfalls of 2008 and 2009) but it may raise rapidly after one good rainy season. As an example, following the $473 \mathrm{~mm}$ rainfall in 2010, the number of individuals reached 37 individuals in 2011, while it has not exceeded 6 in 2010.

\subsection{Individual's Mobility}

The low trapping success as well as the limited recapture rates did not enable us to assess individual mobility for all trapping sessions.

Individual distances between successive (re) captures (DRS) within trapping sessions ranged from $3.3 \mathrm{~m}$ to $12.1 \mathrm{~m}$ with an overall average DRS of $7.8 \mathrm{~m}$ (Table 2). Due to limited sample size, DRS comparisons between sex and age categories have been possible only on average values calculated over all the monitoring period. No significant difference in DRS was found either between males and females $(6.2 \mathrm{~m}$ for males vs. 8.3 for females: $\mathrm{p}=0.127)$ or between young and adult individuals $(8.1 \mathrm{~m}$ for young $v s .7 .3$ for adults; $p=0.085$ ). The maximal distance between (re) captures (DMR) observed within trapping sessions was 28.3 m (February 2008) with an average overall DMR of $14.4 \mathrm{~m}$. Cumulative home ranges were determined considering all capture / recapture data collected $(\mathrm{N}=14)$ over all monitoring periods. Although only 3 individuals (i.e. less than $3 \%$ of the whole sample) were concerned, these home ranges provided some preliminary insights about long-term residents domains: $50 \mathrm{~m}^{2}$ (3 capture/recapture) for an individual who lived at least 8 months on the quadrat; $100 \mathrm{~m}^{2}$ ( 5 capture/recapture) for another one who lived at least 1 year on the quadrat; $450 \mathrm{~m}^{2}$ (6 capture/recapture) for the third individual who stayed for at least 4 months.

Table 2. Estimated individual mobility parameters: average values of DRS and DMR. Numbers of individuals from which DRS and DMR were calculated are shown in parentheses.

\begin{tabular}{lll}
\hline & DRS (m) & DMR (m) \\
\hline February 2008 & $10(1)$ & 10 \\
June 2008 & $7,7(10)$ & 28.3 \\
February 2009 & $8,0(7)$ & 10 \\
June 2009 & $6,0(14)$ & 14,14 \\
June 2010 & $12,1(2)$ & 14,14 \\
June 2011 & $3,3(6)$ & 10 \\
Average & 7,8 & 14,4 \\
\hline
\end{tabular}

\subsection{Population Genetic Structure}

Genetic analyses do not include the subsample for the year 2010 due to its limited size (only 7 individuals over the three sessions of the year). Annual subsamples were constituted by grouping individuals caught within the same year (2008, 2009 and 2011). When an animal was captured at several temporal sessions, it was referred to the sessions of its first capture.

Of the 66 exact tests performed to test for linkage disequilibrium, only $5(7.5 \%)$ were significant after correction for multiple testing. Significant values systematically involved different pairs of loci (data not shown), thus suggesting that the 12 loci can reasonably be considered as independent.

The Gangara population was not at Hardy-Weinberg equilibrium and exhibited significant heterozygote deficiencies, as indicated by the mean positive $F_{I S}$ value of
$0.24(95 \% \mathrm{CI}=[0.11-0.36])$. The allelic richness per locus per population ranged from 2.18 to 13.34 for annual subsamples, with an overall average of 7.34 (Table 3). Median values of Loiselle's kinship coefficients were globally low for each annual subsample (0.0062 for 2008, 0.0026 for 2009, and 0.0011 for 2011), and their distribution is largely unimodal indicating that there is no pairs of individuals which are more related than others (data not shown).

Table 3. Genetic diversity parameters estimated on the whole sample and the annual subsamples 2008, 2009 and 2011. $N=$ Number of individuals; $A_{r}=$ Number of alleles; He and Ho respectively expected and observed heterozygotisies; HWE $(p)=$ probability of HWE deviation test.

\begin{tabular}{llllll}
\hline Sample & $\mathbf{N}$ & $\mathbf{A}_{\mathbf{r}}$ & Ho & He & Fis \\
\hline 2008 & 28 & 6.751 & 0.5062 & 0.6663 & 0.25 \\
2009 & 64 & 6.996 & 0.5041 & 0.6634 & 0.25 \\
2011 & 35 & 6.821 & 0.5392 & 0.6569 & 0.19 \\
All & 134 & 7.340 & 0,508 & 0,686 & 0.24 \\
\hline
\end{tabular}

Estimated pairwise $F_{S T}$ values between annual subsamples 
ranged from 0.0056 to 0.0191 (mean $F_{S T}=0.042,95 \% \mathrm{CI}=$ $[0.11-0.36])$. They indicated small, but significant variations in allelic frequencies between annual sub-samples. IBD was significant $\left(P<0.001 ; R^{2}=0.038\right.$; regression slope $\mathrm{b}=0.014,95 \%$ CI [0.0078-0.0255]; Figure 2).
Using the regression slope value, and a density of 0.0016 individual $/ \mathrm{m}^{2}$ corresponding to the mean density observed in the quadrat, we estimated the mean parent-offspring genetic distances to be $59.5 \mathrm{~m}$.

IBD

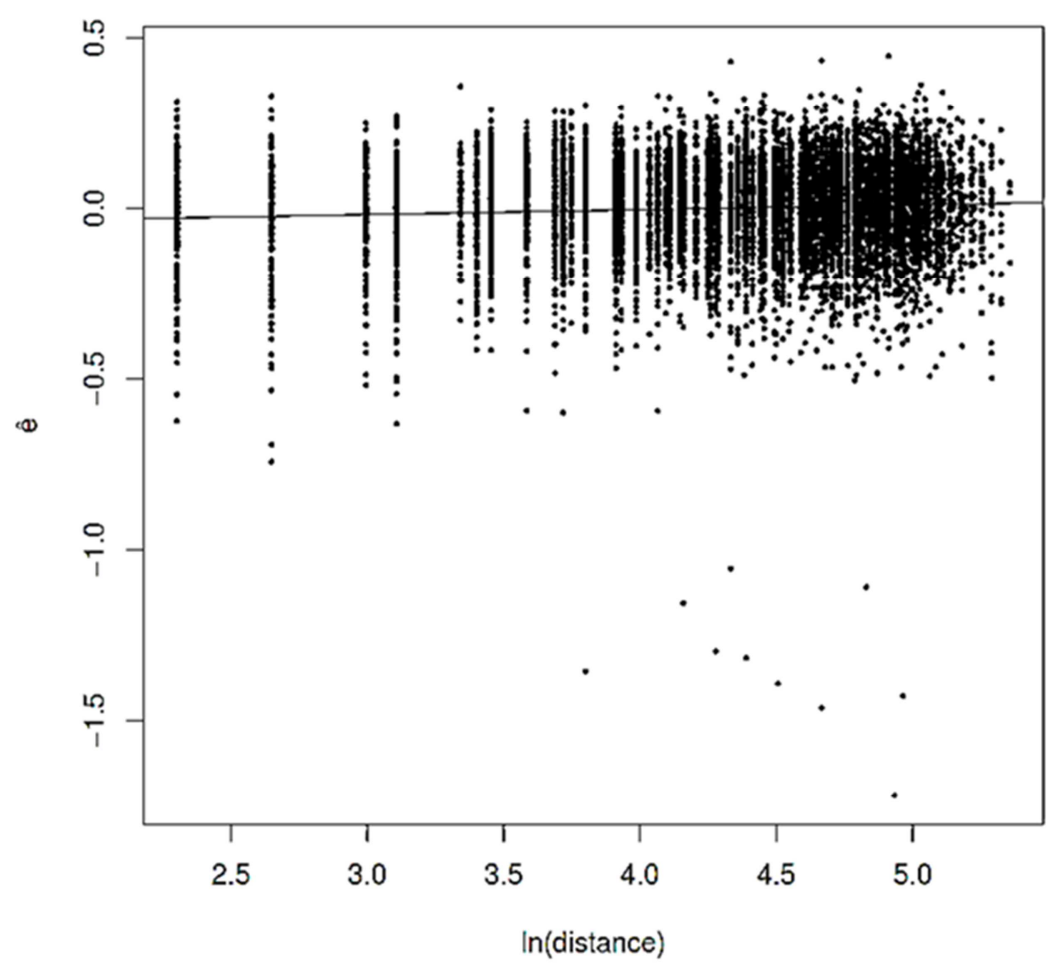

Figure 2. Results of Isolation by Distance (IBD) using Mantel tests correlating log-transformed geographical distances and genetic distances.

$F_{S T}$ values were not significantly different $(\mathrm{p}=0.77)$ between males (mean $\left.F_{S T}=0.0115\right)$ and females (mean $F_{S T}=$ 0.0036). Spatial autocorrelations also indicated similar dispersal patterns for females and males (Figure 3). Effective dispersal distance estimated were of $54 \mathrm{~m}$ (95\% CI: [38 m-90 $\mathrm{m}])$ and $60 \mathrm{~m}(95 \% \mathrm{CI}:$ [39 m-85 m]), for females and males, respectively, and the overlapping confidence intervals suggested that there is no significant difference between sexes.

\section{Discussion}

\subsection{Population Dynamics and Genetic Diversity of G. Nigeriae}

Our study was conducted at a spatial scale (2.25 ha) somewhat smaller than those at which population dynamics and/or genetic surveys are usually carried out in rodents [3338]. Nevertheless, we believe that the grid here considered is well representative of $G$. nigeriae habitat conditions in this area, where millet crops and open savanna on sandy soils dominate in the landscape. Its location has been chosen based on evidence of $G$. nigeriae presence at the site, and further confirmed by trapping investigation prior to the installation of the trapping grid.
Throughout the monitoring period, the recorded numbers of individuals, and consequently population densities, were very low. Limited "trappability" associated with behavioural characteristics (trap avoidance/shyness, social learning...) or unattractiveness of our traps could be put forward as explicative factors for the relatively low number of capture events recorded over the entire study despite an significant trapping effort. Another explanation may reside in our choice of $10 \mathrm{~m}$ as inter-trap interval that is slightly larger than the average DRS retrieved from this study $(7.8 \mathrm{~m})$. Indeed, in theory, trap interval should be less than or equal to the DRS, so that the trapping device allows each individual to encounter at least one trap when foraging in its home range [39]. Nevertheless, much higher densities of $G$. nigeriae were successfully detected in Kollo, western Niger, using a similar protocol [3]. In addition, despite higher trapping success values, the DRS obtained in Kollo $(7.7 \mathrm{~m})$ and in this study were similar. The low trapping success in Gangara $(<2 \%)$ suggests that gerbils were globally rare on our experimental field. Search and excavations of apparently active burrows in the area surrounding our grid (at least 30 burrows excavated per trapping session) largely confirmed the scarcity of gerbils in the area (data not shown). Altogether, these data bring strong support that our protocol enables a reliable reflection of demographic patterns in G. nigeriae from Gangara. 

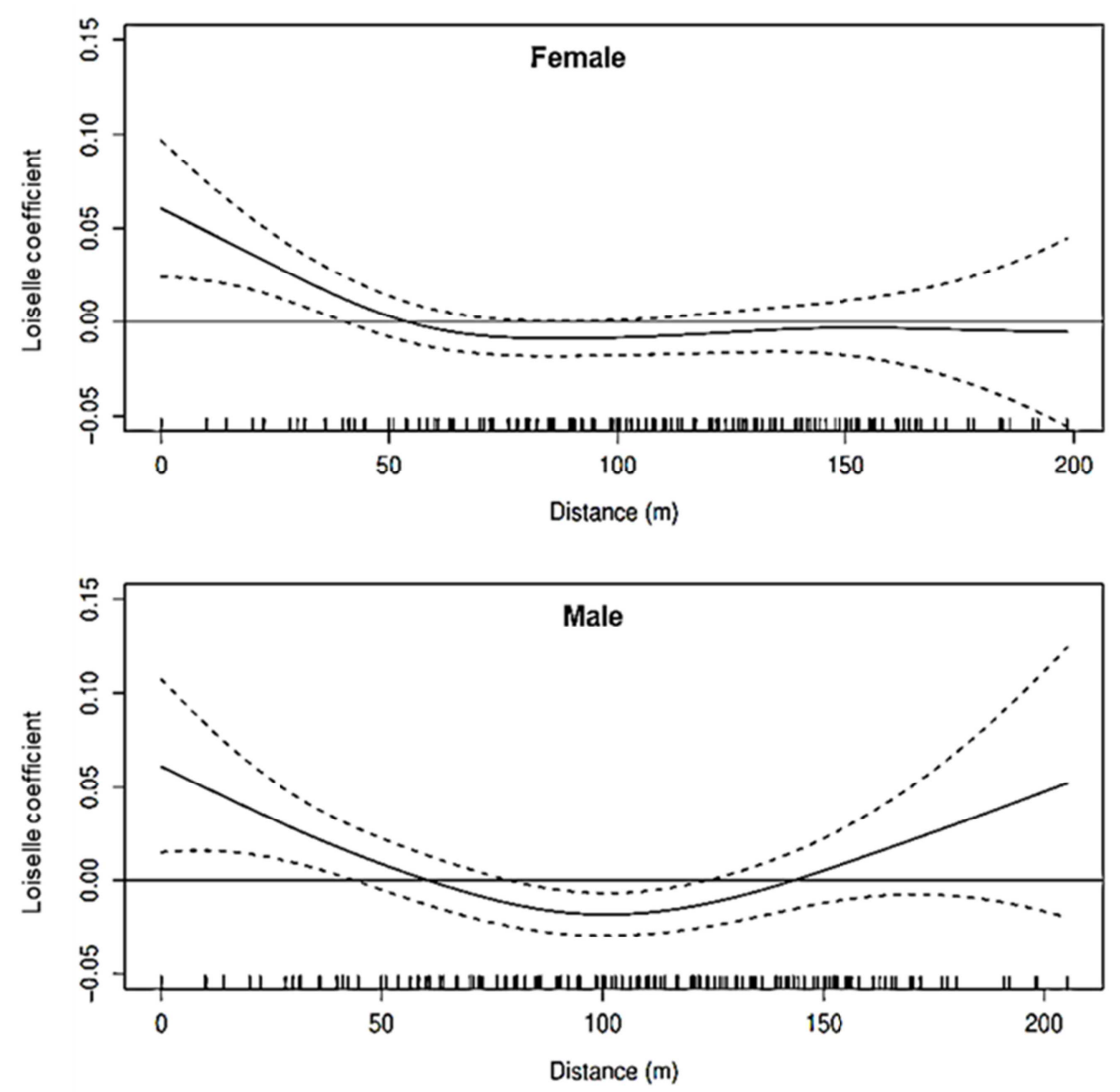

Figure 3. Spatial autocorrelation graphs for sex bias dispersal (male vs female) tests based on Kinship coefficient of Loiselle and geographic distance.

As noted earlier, densities of G. nigeriae are low in the study area. The maximal density value recorded throughout the three and a half year long monitoring period (27.5 gerbils per hectare) was much [less than what was observed in Kollo between 1997 and 2000 (peaks of 120 individuals/ha [4]). Taking into account the very similar protocols used, such density differences between Kollo and Gangara populations can be attributed to geographical (south west $v s$. central east Niger) and/or historical differences (1997-2000 in Kollo vs. 2008-2011 in Gangara). Kollo is located within a typical Sahelian region with an annual rainfall of $500 \mathrm{~mm}$, while Gangara is located further north, between the Sahara and Sahel ecoregions, and receives an average of $350 \mathrm{~mm}$ annually [40] (DMN, 2014). Moreover, Gangara has been more affected by the anthropic and climatic changes than the southernmost zones, with isohyets moving from north to south since the early 1970s and resulting in rarer and more erratic rainfall $[9,41]$. Such a rapid aridification and subsequent degradation of local habitats have induced a loss of biodiversity in northern Sahel [42]. As an example, many plant species have gone extinct locally, probably because they had reached their drought tolerance threshold [43]. Like these plants, G. nigeriae, which is not adapted to Saharan conditions $[44,1,2]$, may also have suffered from recent aridification processes at work along the northern edge of its geographic distribution, such as in the region of Gangara. This impact of climatic and environmental conditions on the evolution of $G$. nigeriae species range may further be exemplified by its occurrence in Southern/Sudanian localities of Niger [12] where it was not known by the inhabitants until recently (Hima, unpublished). Yet, the genetic diversity observed in G. nigeriae from Gangara was higher than that found in the expansion area of the species (e.g. in Senegal, Ndiaye et al. unpublished), and similar to that observed in large-scaled studies focusing on other African rodent species (e.g. in Mastomys [33, 45-47] or Praomys [48]). If low densities of $G$. nigeriae in Gangara are attributed to climatic and environmental changes, such, such processes are probably too recent to be reflected by local genetic diversity levels. Unfortunately, no genetic data are available for Kollo's population, which would have helpful in terms of evaluating whether genetic diversity may reflect the contrasted density levels observed in Gangara and Kollo.

Our results indicate that the G. nigeriae population of Gangara presents a single-phase cycle characterized by important inter- and intra-annual variations. Density peaks appeared towards the end of the dry season, or sometimes even at the beginning of the rainy season. This cycle is closely related to duration and intensity of the rainy season with heavy rainfall on year $\mathrm{N}$ leading to earlier and more important reproduction in year $\mathrm{N}+1$. Similar results were found in another gerbilline rodent species, namely Taterillus pygargus, in semi-arid regions of Senegal [49]. A population dynamics pattern with a unique peak of density at the beginning of the rainy season was also noted in $G$. nigeriae from Northern Burkina Faso [8]. In contrast, in Kollo 
(southwestern Niger), G. nigeriae abundance cycle seems biphasic and unbalanced, including two distinct periods of abundance with varying intensities and durations [3]. The first, less marked and shorter, corresponds to the end of the dry season / beginning of the rainy season, while the second one, characterized by higher densities over longer periods, is observed between November and February. Such a pattern showing two maxima and two minima is generally typical of rodents from tropical regions characterized by two rainy seasons $[50,51]$. In our study, however, the time period that separated consecutive sessions (4 months) may have been too long to highlight a biphasic cycle. Indeed, when comparing the results obtained in Southwestern (Kollo) and central east (Gangara) Niger at the only periods when trapping occurred in Gangara (February, June and November), the abundance cycles of the Kollo and Gangara populations appear similar, suggesting that the cycle could also be biphasic in Gangara. Abundance cycles, if they exist, may contribute to explain the significant heterozygote deficiencies observed if they lead to genetically different cohorts through the year [52]. However, estimated pairwise $F_{S T}$ values between annual subsamples were very low, indicating weak differentiation between annual subpopulations, hence between generations.

The weak low abundance of $G$. nigeriae in eastern Niger during some periods may be due to a possible estivation of gerbils as already observed in northern Burkina Faso [53, 54]. No estivation was mentioned in G. nigeriae from Kollo [3], but contrasted aridity levels could lead to differences in life cycle between populations. In support of the estivation hypothesis in G. nigeriae from Gangara, important quantities of cultivated and wild grass seeds (e.g. Pennisetum spp., Sorghum spp., Cenchrus biflorus, Cymbopogon gayanus) were found stored in the numerous galleries of the excavated burrows. Food storage inside burrows may also partly explain our low trapping success, via a reduction of the mobility of gerbils rather feeding on stocked food than attracted by the bait.

\subsection{Mobility and Dispersal Capacities}

Dispersal can be estimated either directly by CMR, or indirectly using genetic markers for inferring differentiation between individuals in both space and time $[55,56]$. Here, both approaches were used and found to be quite congruent in their conclusions. First, our CMR results show that gerbils from central-east Niger are not very mobile with DRS values ranging from 3.3 to $12.1 \mathrm{~m}$ (average $7.8 \mathrm{~m}$ ) and DMR values ranging from 10 to $28.3 \mathrm{~m}$ (average $14.4 \mathrm{~m}$ ). The individuals thus seems to live on and explore only very small home range. This is perfect agreement with what was observed in south-west Niger (average DRS of $7.7 \mathrm{~m}$ and average DMR of $24.8 \mathrm{~m}$ ) despite higher densities and a slightly different annual cycle of abundance [3]. These small home ranges may result in spatial structure, and explain the heterozygotes deficiencies observed, as already shown for instance in desert rodents [57]. The significant IBD pattern detected in Gangara confirms the limited dispersal abilities of $G$. nigeriae at the scale of the trapping grid. Indeed, significant IBD is usually associated with low individual dispersion capacities, especially when individuals are genealogically and geographically close, i.e. on a reduced spatio-temporal scale $[58,59]$. We showed here that dispersal is limited for both females and males, although the latter is usually the most dispersing sex in mammals [60]. Low dispersal abilities should theoretically result in high inbreeding. At the scale of the quadrat, the unimodal distribution of kinship coefficients did not enable to reconstruct different family groups. Further investigations would be required to better understand spatial structure and mate choice strategies of this species with limited dispersal abilities but relatively high genetic diversity levels.

In short, G. nigeriae population dynamics results are very consistent wherever they are obtained in Kollo [4] or Gangara (this study) which are characterized by two very distinct chromosomal variants [2]. They show that the species may display different demographic patterns in the two areas, but share the same low mobility. They highlight that, whatever the cytotype, $G$. nigeriae has one of the lowest mobility ever documented in sudano-sahelian rodent species (e.g. average DRS values of G. gerbillus, G. nanus, Mastomys erythroleucus, Taterillus gracilis and Gerbilliscus guineae are of 10.7, 16.9, 17.7, 19.5 and $20.5 \mathrm{~m}$, respectively $[61,1])$. In contrast with its low dispersal abilities in Niger, the expansion of $G$. nigeriae in Northern Senegal seems to be very rapid, probably as a result of the opening environment and increased aridity driven by anthropo-climatic changes ([62]; Granjon et al. unpublished). The reason for such a difference remains to be investigated.

\subsection{Implications for G. Nigeriae Control as a Rodent Pest}

In the central-east region of Niger, G. nigeriae may be at the limit of its distribution range. As aridity increases, the local persistence of the species may become difficult, and gradual extinction may occur. No evidence exist about a potential distribution shift from north to south in Niger, as seems to be the case between Mauritania and North Senegal [62]. However, if this was to be the case in Niger too, the impacts in terms of damage to crops would be probably significant since the southern regions are currently the main cereal production areas in the country.

In view of the low mobility and limited-dispersal capacities of $G$. nigeriae in Niger, locally-designed (i.e. at the field or village scales) control strategies against this rodent pest appear conceivable. Such rodent control campaigns could be carried out during low population's densities periods which are now well characterized whatever the chromosomal pool (i.e. high vs. low diploid numbers) / geographical region (west vs. east of Niger) considered. Specifically, the control should be conducted between January and May when densities are low and when farming activities are at their lowest. Nevertheless, before launching any control activities, it would first be necessary to evaluate its cost-benefit ratio [63]. Indeed, it may happen that, below a certain threshold of pest density, the damage caused may be less costly than the control procedure itself. 
Interestingly, traditional traps known as "Kornaka" traps (which are quite similar to pitfall traps) could be used for controlling rodent populations in Niger. Indeed, a preliminary test of these traps showed that they could significantly reduce gerbil densities (37 captures in 3 nighttraps with 49 "Kornaka" traps versus 22 captures in 5 nighttraps with 256 wire mesh traps; Hima et al. unpublished). As such, "Kornaka" traps may be an effective, cheap and accessible alternative for the control of pest gerbils by vulnerable Sahelian farmers.

\section{Conclusion}

Our results showed that in the Central Sahel, G. nigeriae populations are characterized by very low population densities with a single-phased abundance cycle which was strongly dependent on rainfall patterns. We also found that mobility parameters indicated very low individual mobility. In addition, genetic analyses revealed spatial structuration, thus confirming rather poor dispersal capacity. So, in terms of control, our results suggested that, locally-designed control strategies appear conceivable, in view of the low mobility and limited-dispersal capacities of $G$. nigeriae in Niger. Specifically, control measures should be conducted between January and May when densities are low and when farming activities are at their lowest. Interestingly, traditional traps known as "Kornaka" traps could be an effective, cheap and accessible alternative for this control by vulnerable Sahelian farmers.

\section{Acknowledgements}

This work has been support by IRD for the data collection, then by UAM and JEAI-IBAO for genetic analyses which were performed at the CBGP. Data used in this work were partly produced through the GenSeq technical facilities of the «Institut des Sciences de 1'Evolution de Montpellier», with the support of LabEx CeMEB, an ANR "Investissements d'avenir" program.

We are very grateful to J. M. Duplantier as well as A. Doumma for their help and their early comments on the manuscript. We also thank C. Tatard, M. Garba and S. Gagare for their assistance in field and/or laboratory works and K. Berthier for her help in genetic data analyses. We are extremely grateful to Gangara inhabitants and farmers for their warm welcome and help during the field surveys. Special thanks go to Oumarou who provided us free access to its crop field during the three and a half years period of our study.

\section{References}

[1] Granjon, L., Duplantier, J-M. (2009). Les rongeurs de l'Afrique sahélo-soudanienne. IRD/MNHN (eds.). 215 pp.

[2] Hima, K., Thiam, M., Catalan, J., Gauthier, P., Duplantier, J. M., Piry, S., Sembène, M., Britton-Davidian, J., Granjon, L.,
Dobigny, G. (2011). Extensive Robertsonian polymorphism in the African rodent Gerbillus nigeriae: geographic aspects and meiotic data. Journal of Zoology, 284: 276-285.

[3] Nomao, A. (2001). Contribution à la connaissance des rongeurs du Niger. Caractéristiques biologiques et écologiques d'une population de Gerbillus nigeriae (Rodentia Gerbillinae), dans la ferme de Kollo (Niger). Doctorat de 3ème cycle, Université Abdou Moumouni de Niamey. 215 pp.

[4] Nomao, A., Gautun, J. C. (2001). Dynamique de l'abondance et reproduction de Gerbillus nigeriae (Rodentia, Gerbillinae) dans la ferme de Kollo (Niger). African small mammals: 481498.

[5] Hima, K. (2010). Biologie évolutive de Gerbillus nigeriae (Rodentia, Gerbillinae), principal ravageur des cultures céréalières au Niger: aspects chromosomique, morphométrique et populationnel. Thèse de Doctorat, UAM, Niamey. 194 pp.

[6] DGPV, Direction Générale de la Protection des Végétaux, Ministère du Développement Agricole (2008). Bulletin Phytosanitaire de la Direction Générale de la Protection des Végétaux-MDA, Niger: Synthèse 1995 à 2008.

[7] Krebs, C. J., 1999. Current paradigms of rodent population dynamics - what are we missing? In: G. R. Singleton, L. A Hinds, H. Leirs \& Z. Zhang (Eds), Ecologically-based management of rodent pests. Australian Center for International Agricultural Research (ACIAR), Canberra, pp. 33-48.

[8] Sicard, B. (1987). Mécanismes écologiques et physiologiques de régulation des variations de la dynamique des populations des rongeurs sahéliens (Burkina Faso). Thèse de Doctorat d'Etat, USTL, Montpellier II. 303 pp.

[9] Lebel, T., Ali, A. (2009). Recent trends in the Central and Western Sahel rainfall regime (1990-2007). J. Hydrol. 375: 14-33.

[10] Volobouev, V., Viegas-Péquignot, E., Petter, F., Gautun, J. C., Sicard, B. \& Dutrillaux, B. (1988). Complex chromosomal polymorphism in Gerbillus nigeriae. Journal of Mammalogy 69: 131-134.

[11] Dobigny, G., Nomao, A., Gautun, J. C. (2002). A cytotaxonomic survey of Rodents from Niger: implications for systematics, biodiversity and biogeography. Mammalia 66 (4): 495-523.

[12] Gauthier, P., Hima, K., Dobigny, G. (2010). Robertsonian fusions, pericentromeric repeat organization and evolution: a case study within a highly polymorphic rodent species, Gerbillus nigeriae. Chromosome Research 18: 473-486.

[13] Dobigny, G., Britton-Davidian, J. and Robinson, T. J. (2017). Chromosomal polymorphism in mammals: an evolutionary perspective. Biol. Rev. 92, 1-21.

[14] Sikes, R. S., Gannon, W. L., and the Animal Care and Use Committee of the American Society of Mammalogists (2011). Guidelines of the American Society of Mammalogists for the use of wild mammals in research. Journal of Mammalogy, 92 (1): 235-253.

[15] Krebs, C. J. (1966). Demographic changes in fluctuating populations of Microtus californicus. Ecological Monographs 36: 239-273. 
[16] Byrne, A. W., Do Lin San, E. (2016). A cautionary note on the use of minimum number alive-derived trappability metrics in wildlife programmes, as exemplified by the case of the European badger (Meles meles). Wildlife Biol. in Practice 12 (3): 51-57.

[17] Kaufman, D. W., Gentry, J. B., Kaufman, G. A., Smith, M. H., Wiener, J. G. (1978). Density estimation of small mammals: comparison of techniques utilizing removal trapping. Acta Theriol. 23 (7): 171-197.

[18] Creel, S. and Creel N. M. (2002). The African Wild Dog: Behavior, Ecology, and Conservation. Princeton University Press, Princeton, New Jersey, 341 p.

[19] Rurik, L. and Macdonald D. W. (2003). Home range and habitat use of the kit fox (Vulpes macrotis) in a prairie dog (Cynomys ludovicianus) complex. J. Zool., 259: 1-5.

[20] Thiam, M., Hima, K., Gauthier, P., Tatard, C., Duplantier, J. M., Dobigny, G., Granjon, L., Dalecky, A., Bâ, K., Sembène, M., Brouat, C. (2010). Isolation and characterization of microsatellites in Gerbillus nigeriae. Molecular Ecology Resources.

[21] Rousset, F. (2008). Genepop 7: a complete re-implementation of the genepop software for Windows and Linux. Molecular Ecology Resources 8 (1): 103-106.

[22] Benjamini, Y. and Hochberg, Y. (1995). Controlling the False Discovery Rate: A Practical and Powerful Approach to Multiple Testing. Journal of the Royal Statistical Society. Series B: Methodological, Vol. 57, No. 1, pp. 289-300.

[23] Dabney, A., Storey, J. D., Warnes, G. R. (2011). Q-value estimation for false discovery rate control. $\mathrm{R}$ package v1.2.0. R Foundation for Statistical Computing.

[24] Nei, M. (1978). Estimation of average heterozygosity and genetic distance from a small number of individuals. Genetics, 89: 583-590.

[25] Weir, B. S., Cockerham, C. C. (1984). Estimating F-statistics for the analysis of population structure. Evolution, 38: 13581370 .

[26] Goudet, J. (2001). FSTAT, version 2.9. 3, a program to estimate and test gene diversities and fixation indices. Lausanne University, Switzerland.

[27] Hardy, O. J., and X. Vekemans (2002). SPAGeDi: a versatile computer program to analyse spatial genetic structure at the individual or population levels. Molecular Ecology Notes 2: 618-620.

[28] Loiselle, B. A., V. L. Sork, J. Nason and C. Graham (1995). Spatial genetic structure of a tropical understory shrub, Psychotria officinalis (Rubiaceae). American Journal of Botany 82: 1420-1425.

[29] R Core Team (2018). R: A language and environment for statistical computing. R Foundation for Statistical Computing, Vienna, Austria.

[30] Watts, P. C., Rousset F., Saccheri, I. J. et al. (2007). Compatible genetic and ecological estimates of dispersal rates in insect (Coenagrion mercuriale: Odonata: Zygoptera) populations: analysis of 'neighbourhood size' using a more precise estimator. Molecular Ecology, 16, 737-751.

[31] Rousset, F. (2000). Genetic differentiation between individuals. Journal of Evolutionary Biology, 13: 58-62.

[32] Leblois, Raphael, Arnaud Estoup, and François Rousset (2003). Influence of Mutational and Sampling Factors on the Estimation of Demographic Parameters in a Continuous Population under Isolation by Distance. Mol. Biol. Evol. 20: 491-502.

[33] Granjon Laurent, Cosson Jean-François, Quesseveur Erwan, Sicard Bruno, (2005). Population dynamics of the multimammate rat Mastomys huberti in an annually flooded agricultural region of central Mali. J. of Mammalogy, 86 (5): 997-1008.

[34] Brouat, C., Loiseau, A., Kane, M., Bâ, K., Duplantier, J. M. (2007). Population genetic structure of two ecologically distinct multimammate rats: the commensal Mastomys natalensis and the wild Mastomys erythroleucus in southeastern Senegal. Mol. Ecol. 200716 (14): 2985-97.

[35] Van Hooft P., Cosson, J. F., Vibe-Petersen, S. and Leirs, H. (2008). Dispersal in Mastomys natalensis mice: use of finescale genetic analyses for pest management. Hereditas 145: 262-273.

[36] Gauffre, B., Berthier, K., Inchausti, P., Chaval, Y., Bretagnolle, V., Cosson, J-F. (2014). Short-term variations in gene flow related to cyclic density fluctuations in the common vole. Molecular Ecology, 23, 3214-3225.

[37] J. B. Mangombi, C. Brouat, A. Loiseau, O. Banga, E. M. Leroy, M. Bourgarel, J.-M. Duplantier. (2016). Urban population genetics of the invasive black rats in Franceville, Gabon. Journal of Zoology, 299, 183-190.

[38] Berthier, K., Garba, M., Leblois, R., Navascues, M., Tatard, C., Gauthier, P., Gagare, S., Piry, S., Brouat, C., Dalecky, A., Loiseau, A., and Dobigny, G. Black rat invasion of inland Sahel: insights from interviews and population genetics in south-western Niger. Biological Journal of the Linnean Society, 119, 748-765.

[39] Spitz, F. (1969). L'échantillonnage des populations des petits mammifères. In: L'échantillonnage des peuplements animaux des milieux terrestres. Lamotte et Bourlière (eds.), Masson, Paris. 153-188.

[40] Direction de la Météorologie Nationale du Niger. (2014). Zones climatiques du Niger et cumuls pluviométriques correspondants. Bulletin de la DMN (2014), $2^{\text {ème }}$ trimestre, 17 pages.

[41] Lebel, T., Cappelaere, B., Galle, S., Hanan, N., Kergoat, L., Levis, S., Vieux, B., Descroix, L., Gosset, M., Mougin, E., Peugeot, C., Seguis, L. (2009). AMMA-CATCH studies in the Sahelian region of West-Africa: An overview. J. Hydrol. 375 (1-2): 3-13.

[42] Miehe, S., Kluge, J., von Wehrden, H., Retzer, V. (2010). Long-term degradation of Sahelian rangeland detected by 27 years of field study in Senegal. Journal of Applied Ecology 47: 692-700.

[43] Maranz, S. (2009). Tree mortality in the African Sahel indicates an anthropogenic ecosystem displaced by climate change. Journal of Biogeography 36: 1181-1193.

[44] Dobigny, G. (2002). Inventaire et Biogéographie des rongeurs du Niger: Nuisances aux cultures, implications dans certains problèmes de santé publique et vétérinaires. Rapport de Coopération pour le Service National. 71 pp. 
[45] Granjon Laurent and Cosson Jean-François. (2008). Social relationships in Mastomys huberti as deduced from field and genetic analyses of multiple capture data. Mammalia 72: 161168.

[46] Lalis A, Leblois R, Lecompte E, Denys C, ter Meulen J, Wirth $\mathrm{T}$ (2012). The impact of human conflict on the genetics of Mastomys natalensis and Lassa virus in West Africa. Plos One 7, e37068.

[47] Gryseels, S., Gouy De Bellocq, J., Makundi, R., Vanmechelen, K., Broeckhove, J., Mazoch, V., Sumbera, R., Zimajr, J., Leirs, H. \& Baird, S. J. E. (2016). Genetic distinction between contiguous urban and rural multimammate mice in Tanzania despite gene flow. J. Evol. Biol. 29: 1952-196.

[48] Bryja, J., Granjon, L., Dobigny, G., Patzenhauerovà, H., Konečný, A., Duplantier, J. M., Gauthier, P., Colyn, M., Durnez, L., Lalis, A. \& Nicolas, V. (2010). Plio-Pleistocene history of West African Sudanian savanna and the phylogeography of the Praomys daltoni complex (Rodentia): The environment / geography / genetic interplay. Molecular Ecology, 19: 4783-4799.

[49] Poulet, A. R. (1982). Pullulation de rongeurs dans le Sahel. Mécanismes et déterminisme du cycle d'abondance de Taterillus pygargus et Arvicanthis niloticus (Rongeurs, Gerbillidés et Muridés) dans le Sahel du Sénégal de 1975 à 1977. Thèse de Doctorat d'Etat, Univ. Paris VI. 367 pp.

[50] Gautun, J. C. (1981). Ecologie des rongeurs de savane en moyenne Côte d'Ivoire. Thèse de Doctorat d'Etat ès Sc. Naturelles, Univ. Pierre \& Marie Curie Paris VI. 165 pp.

[51] Dosso, H. (1983). Rongeurs des forêts hygrophiles conservées et des zones anthropisées de la Côte d'Ivoire méridionale. Thèse de Doctorat, Univ. d'Abidjan. 249 pp.

[52] De Meeûs Thierry. (2018). Revisiting $\mathrm{F}_{\mathrm{IS}}$, $\mathrm{F}_{\mathrm{ST}}$, Wahlund Effects, and Null Alleles, Journal of Heredity, Vol. 109: 4, 446-456.

[53] Sicard B., Fuminier F. (1994). Relations entre les variations saisonnières du métabolisme hydrique, l'estivation et la reproduction chez Gerbillus nigeriae et Taterillus petteri (Rodentia, Gerbillidae). Comptes rendus de l'Académie des sciences, sciences de la vie, Paris, 317: 231-238.
[54] Sicard B., Papillon Y. (1996). Water redistribution and the life cycle of Sahelian rodents. Mammalia, 60: 607-617.

[55] Fletcher, D., Dawson, S., Slooten, E. (2002). Designing a mark- recapture study to allow for local emigration. Journal of Agricultural, Biological and Environmental Statistics 7 (4): 586-593.

[56] Perret, N., Pradel, R., Miaud, C., Grolet, O., Joly, P. (2003). Transience, dispersal and survival rates in newt patchy populations. Journal of Animal Ecology 72: 567-575.

[57] Flores-Manzanero, A., M. A. Luna-Barcenas, R. J. Dyer and E. Vazquez-Dominguez (2018). Functional connectivity and home range inferred at a microgeographic landscape genetics scale in a desert-dwelling rodent. Ecology and Evolution 9: 437-453.

[58] Wang, G., Liu, W., Wang, Y., Wan, X., and Zhong, W. (2017). Restricted dispersal determines fine-scale spatial genetic structure of Mongolian gerbils. Current Zoology, 63 (6): 687691.

[59] Aguillon, S. M., Fitzpatrick, J. W., Bowman, R., Schoech, S. J., Clark, A. G., Coop, G., Chen, N. (2017). Deconstructing isolation-by-distance: The genomic consequences of limited dispersal. PLoS Genet 13 (8): e1006911.

[60] Mabry, K. E., E. L. Shelley, K. E. Davis, D. T. Blumstein and D. H. van Vuren (2013). Social Mating System and SexBiased Dispersal in Mammals and Birds: A Phylogenetic Analysis. PloS One 8: e57980.

[61] Hubert, B. (1977). Ecologie des populations des rongeurs de Bandia (Sénégal), en zone sahelo-soudanienne. Terre et Vie 31: 33-100.

[62] Thiam, M., Ba, K., Duplantier, J-M. (2008). Impacts of climatic changes on small mammal communities in the Sahel (West Africa) as evidenced by owl pellet analysis. African Zoology, 43 (2): 135-143.

[63] Skonhoft, A., Leirs, H., Andreassen, H. P., Mulungu, L. S. A., Stenseth, N. C., (2006). The bioeconomics of controlling an African rodent pest species. Environment and Development Economics 11: 453-475. 